\title{
Inpatients disease and trends
}

\begin{abstract}
Background: To analyze the major health problems and trends among hospitalized children in a medical center in the 10 years period.

Methods: We retrospectively reviewed all records of patients younger than 18 years who admitted to the Chang Gung Memorial's Hospital between January 1, 2003, and December 31,2012 . The study was composed of categories about the diagnosis, age and gender. We collected and utilized data to examine the leading diagnostic categories and trends by age in the 10 years period.

Results: Children had age differences among hospitalized diagnoses categories. Prematurity or condition from the perinatal periods and congenital anomaly were the top two hospitalized disease categories in newborn. Acute respiratory tract infection was the major diagnoses category in infant. Acute intestinal infectious disease was the top diagnosis in children aged between 1 to 2 years old. Pneumonia was leading diagnoses of children aged in 2 to 6 years and in 6 to 12 years. Fracture was the leading cause of adolescents aged in 12 to 18 years. Congenital anomaly decrease in infant stage but pneumonia still threatened children aged in 2 to 6 years and 6 to 12 years.
\end{abstract}

Conclusions: The characteristics of major health problems were different among age variables in children. All health promotion programs and policies should effectively provide the respective services and measure the outcome efficiently.
Volume 5 Issue 2 - 2016

\author{
Yi-Jung Chang, Dah-Chin Yan, Jing-Long \\ Huang \\ Department of Pediatrics, Chang Gung University College of \\ Medicine, Taiwan
}

\begin{abstract}
Correspondence: Jing-Long Huang MD, Department of Pediatrics, Chang Gung Memorial Hospital, 5 Fu-Hsin Street, Kwei-Shan 333, Taoyuan, Taiwan, Tel 886 -3-328I200, Fax 886-33288957, Email long@cgmh.org.tw
\end{abstract}

Received: August 03, 2016 | Published: August 17, 2016

Keywords: hospitalization, children, trend

\section{Introduction}

With the aging of society, the composition of the disease occurs within society changed. ${ }^{1}$. It is imperative to obtain diseases trends to better understand health care needs of children under the low birth rate. Because of the vital role of admission in health care, it is important to monitor changes in the inpatients to identify trends or problems for improvement. Few studies focus on trends for children in the hospital use but most in the United States. ${ }^{2-5}$ The health care for children and youth varied by insurance status, and region. To our knowledge, no studies discuss the hospital inpatient care of children in Taiwan. The objectives of the current study were to estimate trends of inpatients diagnosis and disease in children in our hospital.

By identifying trends of the health care utilization for children services, health promotion programs and policies could effectively provide the respective services to improve the outcome.

\section{Materials and methods}

Subjects were patients younger than 18 years who were hospitalized at Chang Gung Memorial's Hospital, a medical center of northern Taiwan, during the 10-years periods from Jan 2003 until Dec 2012. In total, 226,175 inpatients from Chang Gung Memorial's Hospital Medical Information Database were identified. The study was composed of annual categories about the diagnosis code, age and gender. The following items were examined: 1) gender and age, 2) diagnosis, 3) inpatients number. Diagnoses are defined from the International Classification of Diseases, Ninth Revision, Clinical Modification (ICD-9-CM) diagnosis codes. Age-specific and genderspecific population estimates for 2003-2012 were obtained. The age was divided into six groups: aged under1 month, in 1 - 12 months, in 1 - 2 years, in 2- 6 years, in 6 - 12 years, and in 12 to 18 years referring by hospital medical records. Analyses for types and changes in inpatient diagnosis between 2003 and 2012 were conducted by access the inpatient number and population ratios. We defined the diagnosis with health newborn cases as ICD-9-CM Code V30-V39, condition originating in perinatal period cases as ICD-9-CM Code 764-779, congenital anomalies cases as ICD-9-CM Code 740-759, acute respiratory infection cases as ICD-9-CM Code 460-466, acute gastroenteritis cases as ICD-9-CM Code 555-558 and 001-009, pneumonia cases as ICD-9-CM Code 480-487, fracture cases as ICD9-CM Code 810-829 and 800-804, arthropathy cases as ICD-9-CM Code 710-719, and musculoskeletal deformities cases as ICD-9-CM Code 730-739.

We have examined the trends of leading diagnostic categories by age and gender group and utilization of hospital inpatient services with annual inpatients change. The software of SPSS 17 for Windows was used for data management and statistics. Statistical investigations were performed with Poisson analysis. All differences discussed in the text are statistically significant at the 0.05 .

\section{Results}

\section{Types of disease}

There were 128,241 male (56.7\%) and 97,934 female (43.2\%), with a ratio of males to females of 1.3:1. The largest inpatient age group was the 6-12 years (25.4\%), followed by newborn $(21.1 \%)$, $1-12$ months $(14.6 \%), 2-6$ years $(14.4 \%), 12-18$ years $(12.1 \%)$ and $1-2$ years $(12.1 \%)$. Table 1 illustrated the leading diagnosis by age and gender from 2003 to 2012.Children had age differences among hospitalized diagnoses categories. From the 2003 to 2102, health newborn (77.6\%), and prematurity or condition from the perinatal periods $(15.1 \%)$ were the top two significant hospitalized diagnoses categories in newborn. Acute respiratory infection (19.1\%) was the major significant diagnoses category aged in 1 to 12 months. Acute gastroenteritis $(18 \%)$ was the significant top diagnosis in children aged in 1 to 2 years. Pneumonia was the significant leading diagnoses 
of children aged in 2 to 6 years and 6 to 12 years $(20.5 \%$ and 15.5 $\%$ ), respectively. During the adolescents, fracture $(6.7 \%)$ was the most common inpatients diagnosis. Newborn with congenital anomalies and adolescents aged 12-18 years with fracture or arthropathy had gender difference among the age group.

\section{Trends over time}

Compared 2003 and 2012, total annual inpatients significantly decreased from 22,403 to 20,875 , a decrease of $6.8 \%$. The largest age

Table I Leading Disease by Age and Gender from 2003 to 2012 group with a significant change was the 1 to 12 month age group, with a decline of $25.1 \%$. Table 2 showed the time charts for 3 leading conditions by age group. Among children aged in 1-12 months, congenital anomalies significantly declined $(18.8 \%$ to $7.3 \%, p<0.001)$. Alternatively, by the aged in 1 to 2 year, acute gastroenteritis increase ( $14.5 \%$ to $19.1 \%, p=0.008)$. Pneumonia did not significant decrease among 2- to 6-year-old children ( $22.6 \%$ to $21.0 \%, p=0.139)$, but increased among the 6 to 12 age group $(11.1 \%$ to $18.8 \%, p<0.001)$.

\begin{tabular}{|c|c|c|c|}
\hline $\begin{array}{l}\text { Age Group and Disease Group } \\
\text { Aged under I month }\end{array}$ & \multicolumn{2}{|c|}{ Aged under I month } & $p$-value \\
\hline Health newborn & 19563 & 17504 & 0.644 \\
\hline Condition originating in perinatal period & 4164 & 3053 & 0.259 \\
\hline Congenital anomalies & 433 & 584 & $<0.001$ \\
\hline \multicolumn{4}{|l|}{ Aged I-I 2 months } \\
\hline Acute respiratory infection & 4127 & 2191 & 0.201 \\
\hline Acute gastroenteritis & 2334 & 1639 & 0.209 \\
\hline Congenital anomalies & 2200 & 1456 & 0.464 \\
\hline \multicolumn{4}{|l|}{ Aged I-2 years } \\
\hline Acute gastroenteritis & 2838 & 2112 & 0.589 \\
\hline Acute respiratory infection & 2679 & 1618 & 0.21 \\
\hline Pneumonia & 1728 & 1277 & 0.631 \\
\hline \multicolumn{4}{|l|}{ Aged $2-6$ years } \\
\hline Pneumonia & 3546 & 3174 & 0.397 \\
\hline Acute gastroenteritis & 2975 & 2170 & 0.421 \\
\hline Acute respiratory infection & 1827 & 1467 & 0.146 \\
\hline \multicolumn{4}{|l|}{ Aged 6-12 years } \\
\hline Pneumonia & 4585 & 4347 & 0.149 \\
\hline Acute gastroenteritis & 2772 & 1936 & 0.33 \\
\hline Acute respiratory infection & 2211 & 1648 & 0.665 \\
\hline \multicolumn{4}{|l|}{ Aged I $2-18$ years } \\
\hline Fracture & 1410 & 453 & $<0.001$ \\
\hline Arthropathy & 372 & 781 & $<0.001$ \\
\hline Musculoskeletal deformities & 566 & 522 & 0.216 \\
\hline
\end{tabular}

Table 2 Leading Diagnoses for Children, 20I 2 Versus 2003

\begin{tabular}{|c|c|c|c|c|}
\hline & 2003 & & 2012 & \\
\hline Age group and diagnostic group & No & $\%$ & No & $\%$ \\
\hline \multicolumn{5}{|l|}{ Aged under I month } \\
\hline Health newborn & 3749 & 78.7 & 4661 & 82.3 \\
\hline Condition originating in perinatal period & 693 & 14.5 & 782 & 13.8 \\
\hline Congenital anomalies & 119 & 2.4 & 77 & 1.3 \\
\hline \multicolumn{5}{|l|}{ Aged I-I 2 months } \\
\hline Acute respiratory infection & 795 & 21.2 & 497 & 17.6 \\
\hline Congenital anomalies & 705 & 18.8 & 208 & 7.3 \\
\hline Acute gastroenteritis & 369 & 9.8 & 340 & 12 \\
\hline \multicolumn{5}{|l|}{ Aged I-2 years } \\
\hline Acute respiratory infection & 394 & 14.6 & 367 & 16.7 \\
\hline Acute gastroenteritis & 393 & 14.5 & 420 & 19.1 \\
\hline Pneumonia & 372 & 13.8 & 247 & 11.2 \\
\hline \multicolumn{5}{|l|}{ Aged 2-6 years } \\
\hline Pneumonia & 725 & 22.6 & 572 & 21.0 \\
\hline Acute gastroenteritis & 401 & 12.5 & 451 & 16.5 \\
\hline Acute respiratory infection & 234 & 7.3 & 266 & 9.7 \\
\hline \multicolumn{5}{|l|}{ Aged 6-12 years } \\
\hline Pneumonia & 625 & $|I .|$. & 920 & 18.8 \\
\hline Acute gastroenteritis & 290 & 5.1 & 436 & 8.9 \\
\hline Acute respiratory infection & 193 & 3.4 & 286 & 5.8 \\
\hline \multicolumn{5}{|l|}{ Aged $12-18$ years } \\
\hline Fracture & 200 & 7.7 & 154 & 5.8 \\
\hline Musculoskeletal deformities & 121 & 4.7 & 99 & 3.7 \\
\hline Arthropathy & 119 & 4.6 & 99 & 3.7 \\
\hline
\end{tabular}




\section{Discussion}

This report presents a broad review of trends in hospital care for children during the 10-year period from 2003 to 2012. During this time period, significant decreased in inpatients, mirrored by decreases in children at Taiwan. ${ }^{6}$ At neonatal stage, the prematurity or condition from the perinatal periods and congenital anomaly were the top two hospitalized diagnosis categories except the health newborn at our study. The congenital anomaly hospitalization significantly decreased among children, but the prematurity or condition from the perinatal periods did not decrease. The decrease in congenital anomaly may be related to the active screening program or more advanced ultrasound for congenital anomalies in recently. ${ }^{7,8}$ In Taiwan, amniocentesis has been encouraged for pregnant women aged $\geq 35$ years. When chromosomal anomalies or multiple anomalies have been found, most pregnancies have been terminated. ${ }^{9,10}$

In contrast, the newborn with condition originating in perinatal period did not significantly decrease at our study. In our hospital, $18.6 \%$ of the inborn infants were born preterm at annual deliveries. ${ }^{11}$ Preterm infants are at considerable risk for neonatal mortality and morbidities. ${ }^{12,13}$ The incidence of preterm delivery, which has increased in recent years, is associated with various epidemiological and clinical risk factors. ${ }^{14}$ Although the etiology of preterm birth is multi factorial and involves a complex interaction, the health promotion programs and policies should focused on reducing the risk factors of preterm infants to prevent the sequel and cost associated to prematurity.

Congenital anomaly was the major significant diagnoses category aged in 1 to 12 months. Some of the anomalies are not obvious within a few days of birth, such as congenital cardiovascular diseases, hypertrophic pyloric stenosis, and renal, pelvic or ureter obstruction. The lower rates of these anomalies at newborn might be caused by lower detection rates caused by the requirement of early reporting time (within a few days after birth) in Taiwan. ${ }^{9}$ Among children aged in 1 to 2 years, acute gastroenteritis was the significant top diagnosis in children. Acute gastroenteritis is one of the most prevalent infectious diseases in the world. Viral infections, primarily from rotavirus, cause 75 to 90 percent of infectious diarrhea cases in the industrialized world. ${ }^{15}$ Rotavirus and norovirus were detected in $28.6 \%$ patients and $18.1 \%$ patients in our hospital, respectively. ${ }^{16}$ Most infants acquire rotavirus diarrhea early in life; an effective rotavirus vaccine would have a major effect on reducing diarrhea mortality. ${ }^{17-24}$ The introduction of rotavirus vaccines in infants should be considered to reduce severe diarrhea and admission for the disease burden of the major cause of severe childhood gastroenteritis in the past and recent years in our study.

Pneumonia was the significant leading diagnoses of children aged in 2 to 6 years and 6 to 12 years, the largest age group for admission in our study. In Taiwan, pneumonia occurs most frequently below the age of 5 years old, with has an annual incidence of hospitalizations of 3,965 episodes per 100,000 children. 25 In our study, we found a significant decreasing trend in annual ratio of hospitalizations for childhood pneumonia aged in the age group in 2012. This may be related to a conjugated pneumococcal vaccine not been introduced in Taiwan till $2005 .{ }^{25}$ Because the most important bacteria pathogen is S. pneumonia, vaccinations against the micro-organism may help reduce pneumonia's disease burden. ${ }^{26}$

In contrast, in our study, pneumonia most occurred in inpatients aged in 6 to 12 years in 2012. We found a significant increasing trend in annual ratio of hospitalizations for childhood pneumonia aged in the age group compared with 2003. This may because S. pneumonia vaccinations have not been included in Taiwan's National Vaccination
Program and are not universally administered to all children especially in children aged over 5 year old till this year.

In conclusion, the characteristics of major health problems were different among age variables in children. Health promotion programs and policies toward newborns should focus on conditions from the perinatal periods. Respective programs for infant, should emphasis on the acute infectious disease and congenital anomaly. Our study highlights the health promotion programs and policies should effectively provide the respective services to improve the outcome efficiently.

\section{Acknowledgments}

None.

\section{Conflicts of Interset}

None.

\section{References}

1. Noguchi R, Ohishi S, Koga C, et al. Comparison of the inpatients admitted during the recent 5 years (January 1994-December 1998) with those admitted during the previous 5 years (January 1989-December 1993): a clinico-statistical study. Kurume Med. 2005;47(4):291-297.

2. Simpson L, Zodet MW, Chevarley FM, et al. Health care for children and youth in the United States: 2002 report on trends in access, utilization, quality, and expenditures. Ambul Pediatr. 2004;4(2):131-153.

3. Dougherty D, Meikle SF, Owens P, et al. Children's health care in the first National Healthcare Quality Report and National Healthcare Disparities Report. Med Care. 2005;43(3 Suppl): I58-I63.

4. Simpson L, Dougherty D, Krause D. Measuring children's health care quality. Am J Med Qual. 2007;22:80-84.

5. Miller M, Gergen P, Honour M, et al. Burden of illness for children and where we stand in measuring the quality of this health care. Ambul Pediatr. 2005;5(5):268-278.

6. Ma KZ, Norton EC, Lee SY. Declining fertility and the use of cesarean delivery: evidence from a population-based study in Taiwan. Health Serv Res. 2005;45(5 Pt 1):1360-1375.

7. Leung TN, Ching Chau MM, Chang JJ, etal. Attitudes towards termination of pregnancy among Hong Kong Chinese women attending prenatal diagnosis counselling clinic. Prenat Diagn. 2004;24(7):546-551.

8. Souter VL, Nyberg DA, Benn PA, et al. Correlation of secondtrimester sonographic and biochemical markers. J Ultrasound Med. 2004;23(4):505-511.

9. Chen BY, Hwang BF, Guo YL. Epidemiology of congenital anomalies in a population-based birth registry in Taiwan, 2002. J Formos Med Assoc. 2009;108(6):460-468.

10. Garne E, Khoshnood B, Loane M, et al. Termination of pregnancy for fetal anomaly after 23 weeks of gestation: a European register-based study. BJOG. 2010;117(6):660-666.

11. Tsai ML, Lien R, Chiang MC, et al. Prevalence and morbidity of late preterm infants: current status in a medical center of Northern Taiwan. Pediatr Neonatol. 2012;53(3):171-177.

12. Allen MC, Cristofalo EA, Kim C. Outcomes of preterm infants: morbidity replaces mortality. Clin Perinatol. 2011;38(3):441-454.

13. McCormick MC, Litt JS, Smith VC, et al. Prematurity: an overview and public health implications. Annu Rev Publ Health. 2011;32:367-379.

14. Slattery MM, Morrison JJ. Preterm delivery. Lancet. 2002;360(9344):1489-1497. 
15. Acute Gastroenteritis Guideline Team. Cincinnati Children's Hospita Medical Center. Evidence-based care guideline for prevention and management of acute gastroenteritis in children age 2 months to 18 years. December 21, 2011.

16. Chen SY, Tsai CN, Lai MW, et al. Nor virus infection as a cause of diarrhea-associated benign infantile seizures. Clin Infect Dis. 2009;48(7):849-855.

17. Braeckman T, Van Herck K, Raes M, et al. Rotavirus vaccines in Belgium: policy and impact. Pediatr Infect Dis J. 2011;30(1 Suppl):S21-24.

18. Gagneur A, Nowak E, Lemaitre T, et al. Impact of rotavirus vaccination on hospitalizations for rotavirus diarrhea: the IVANHOE study. Vaccine. 2011;29(21):3753-3759.

19. Giaquinto C, Dominiak-Felden G, Van Damme P, et al. Summary of effectiveness and impact of rotavirus vaccination with the oral pentavalent rotavirus vaccine: a systematic review of the experience in industrialized countries. Hum Vaccin. 2011;7(7):734-748.

20. Martinon-Torres F, Alejandro M, Collazo L. Prospective evaluation of indirect costs due to acute rotavirus gastroenteritis in Spain: the ROTACOST study. Hum Vaccin. 2011;7:757-761.
21. Paulke-Korinek M, Kundi M, Rendi-Wagner P. Herd immunity after two years of the universal mas vaccination program against rotavirus gastroenteritis in Austria. Vaccin. 2011;29:2791-2796.

22. Tate JE, Mutuc JD, Panozzo CA, et al. Sustained decline in rotavirus detections in the United States following the introduction of rotavirus vaccine in 2006. Pediatr Infect Dis J. 2011;30(1 Suppl):S30-S34.

23. Trimis G, Koutsoumbari I, Kottaridi C, et al. Hospital-based surveillance of rotavirus gastroenteritis in the era of limited vaccine uptake through the private sector. Vaccine. 2011;29(43):7292-7295.

24. Zeller M, Rahman M, Heylen E, et al. Rotaviru incidence and genotype distribution before and after national rotavirus vaccine introduction in Belgium. Vaccine. 2010;28(47):7507-7513.

25. Wu PS, Chang IS, Tsai FY, et al. Epidemiology and impacts of children hospitalized with pneumonia from 1997 to 2004 in Taiwan. Pediatr Pulmonol. 2009;44(2):162-166.

26. Madhi SA, Levine OS, Hajjeh R, et. al. Vaccines to prevent pneumonia and improve child survival. Bull World Health Organ. 2008;86(5):365-372. 